\title{
Incorporate the rules of social segregation in solutions for the inhibition of the housing bubble in Vietnam
}

\author{
Van Khai Tran ${ }^{1, *}$ \\ ${ }^{1}$ Van Lang University, Faculty of Architecture and Civil Engineering, 45 Nguyen Khac Nhu, District \\ 1, Ho Chi Minh City, Vietnam
}

\begin{abstract}
Unlike the crisis in the U.S. which mainly started from the secondary investors and financial system, a great part of Vietnam's housing bubble was caused by the primary investors. When businesses in Vietnam made lower profits, this led to rush investments in the real estate market, even from those primary investors who are newly established, have a lack of professionalism in housing development and knowledge of urban economics. Many of their projects were not possible to implement, leaving the market frozen with huge numbers of empty plots, houses and apartments. The review of urban sociology theories combining with deep analysis of the situation of Vietnam and the U.S had clarified the causes of the housing crisis in Vietnam. Many housing projects in the country are prepared without incorporating certain physical and social factors, leading to the lack of feasibility, and therefore, largely seen as the origin of the housing crisis. The proposed solution of this research was to incorporate physical and social factors in the projects represented by the correct selection of the appropriate housing status and dwelling quality for each social group.
\end{abstract}

\section{Introduction}

Many economists and researchers in Vietnam have claimed that a country that is deeply integrating into the world economy cannot avoid the consequences of the crisis with specific solutions, therefore proposed that the solutions to recover the housing market should mainly be found in the financial sector similar to the U.S. The consequence of some tight monetary policies to check inflation from the central bank and strengthen control over debt in Vietnam may freeze capital for real estate, putting it into stagnation.

An analysis of the literatures and the materials related to the causes of the housing crisis in Vietnam shows that the lack of feasibility of the housing projects prepared by many of the primary investors is largely blamed for the cause of the bubble.

The research reviews the classical and contemporary theories of the rules of interaction between urban transportation and social segregation on the location of residents. The result of the research conducts the contribution of an effective solution for the formation of feasible

\footnotetext{
* Corresponding author: khaitv@gmail.com
} 
housing projects for each social group, incorporating appropriate physical and social factors, particularly the social and technological infrastructure system to solve the housing crisis.

\section{Literature review of research on the main causes of the housing crisis in the United States and in Vietnam and the solutions proposed to stabilize the real estate sector and broader financial markets}

\subsection{Review of prior research from around the world, particularly in the United States, which has already identified the primary causes of the housing bubble and the financial crisis in the U.S.}

Richard Bookstaber [1] explained why markets in the U.S keep crashing and explored why financial crises are greater than ever before. The author has seen the ghost (a demon) inside the machine and shows us a world where the innovations of the last 30 years have wreaked havoc on markets and cost trillions of dollars. Bookstaber shines a light on what the future holds for a world where capital and power have moved from Wall Street institutions to elite and highly-leveraged hedge funds [1].

Martin Neil Baily, Robert E. Litan and Matthew S. Johnson [2] show the interaction between housing demand in the U.S. and the perception of low risk in housing investment. Further on is the shifting composition of mortgage lending and the erosion of lending standards, economic incentives in the housing and mortgage origination markets as well as the interaction of securitization and the funding of the housing boom, CDos, SIVs, and shortterm borrowing, credit insurance and tremendous growth in credit default swaps are blamed for causing the U.S. housing bubbles [2].

Dean Baker [3] first describes the circumstances under which the housing bubble in the U.S began to grow, then discusses how financial innovations and the lack of a proper regulatory structure allowed the bubble to grow to ever-more dangerous levels and eventually crash in a way that has placed unprecedented strain on the country's financial system. Baker also outlines key principles for reform of the financial system [3].

Gwartney, J., D. Macpherson, R. Sobel and R. Stroup [4] stated that the causes of the financial crisis of 2008 were: A change in mortgage-lending standards; prolonged lowinterest rate policy of the Fed during 2002-2004; the increased debt/capital ratio of investment banks and the high debt/income ratio of households. The research also warned that the current policy is way off track, therefore the keys to sound policy are neutral treatment of both people and enterprises, well-defined property rights, monetary and price stability, open markets, low taxes and control of government spending [4].

Jeff Holt [5] in A Summary of the Primary Causes of the Housing Bubble and the Resulting Credit Crisis showed that the primary cause of the recession was the credit crisis resulting from the bursting of the housing bubble. Further on, he mentions the four primary causes of the housing bubble: Low mortgage interest rates; a low short-term interest rate; relaxed standards for mortgage loans and irrational exuberance. Holt concludes that the combination of these factors caused the U.S. housing bubble to be more extreme and the resulting credit crisis to be more severe [5].

The above research described that the U.S. government's failed regulation housing policies and the top subprime lenders whose loans provided to the secondary realty investors are largely blamed for triggering the housing and financial crisis, and cited the solutions subsequently carried out to inhibit the development of bubbles, and further on to stabilize the real estate and broader financial markets. 


\subsection{Review of research carried out by Nobel laureates who explored the crisis phenomenon in more theoretical terms and in greater depth to locate its causes in the field of psychology}

Nobel laureate Robert J. Shiller [6] argued that accounts of the crisis often seem instead to place the ultimate blame entirely on such factors as growing dishonesty among mortgage lenders; increasing greed among securitizers, hedge funds and rating agencies; or the mistakes of the Fed. [6].

George A. Akerlof and Robert J. Shiller [7], both Nobel prize laureates, in a book titled Animal Spirits, a term borrowed from the writings of John Maynard Keynes, apply behavioral economics to macroeconomic problems such as business cycles, recessions and instabilities in financial markets. The book considers concepts such as confidence, fairness and money illusion. The behavioral economics mentioned in this work is the intersection of psychology and economics in microeconomic decision making [7]. George A. Akerlof and Robert J. Shiller agree that the ultimate cause of the global financial crisis is the psychology of the real estate bubble, which has certainly been expressed before, but most people have not taken this view to heart, and at the very least they do not appreciate all of its ramifications.

The Ho Chi Minh City Real Estate Association has warned that the housing crisis in Vietnam is not real and is driven by rumors and speculations when land prices skyrocketed in many outlying districts.It has asked the city authorities to make any urban development plans clear and transparent to prevent brokers and land speculators from creating such bubbles [8].

\subsection{Review of research that identifies the situation and causes of the housing crisis in Vietnam}

S.N. Jehan and Thanh Nga Luong [9] argued that Vietnam's real-estate market is a young but fast-growing market faced with the fundamental problems of a new market such as inefficient legal frameworks, lack of transparency, particularly lacking in professionalism and financing sources. The research proposed that the potential policy solutions to these problems include governmental actions to improve market conditions and a long-term solution focusing on real estate securitization [9].

Le Hong Nhat[10] based on the general idea of the main three schools of financial alleviation in the world, suggested that the lessons necessary for supervising financial processes which could be applied to Vietnam and proposed sound financial solutions to take full advantage of development opportunities as well as integrations into the global economy in the future [10].

Dang Huu Man [11] with an analysis of real-world situations, causes and effects of the U.S. credit crisis, showed that the U.S. sub-prime housing mortgage crisis has some negative effects on the world's financial markets and further on impacted upon the world's economic growth, particularly in the international investment capital flow. Based on the analysis of the causes and effects of the crisis in the real world that Vietnam cannot avoid, the paper suggested solutions to the fund lending of real estate projects when the security market is still on the trend of declining and the inflation rate is relatively high [11].

However, Minister of Construction Nguyen Hong Quan [12], in a report to the Vietnam National Assembly in October, 2008 noted that a cause of the housing crisis also is that many financially incapable enterprises lacking experience also entered the housing market with little professionalism. Mr. Quan stated that most of them are newly established or from unrelated fields such as garments and textiles, petroleum and agriculture. Actually many spontaneous investments were not carefully planned, making the market imbalanced and unstableand stimulating speculation as well as creating illusory demand [12]. 
Data from the Ministry of Construction showed that in 2012, 17,000 property companies posted losses. More than 2,600 construction and real estate firms also shut down by the end of the year.Accordingly, the statistical data at the end of quarter 2/2014 provided by the Ministry of Construction showed that the instock rate of real estate products is equivalent to 92.690 billion VND, in which Hanoi contributed 3.096 low-rise apartments, mainlyfrom projects located far away from the $\mathrm{CBD}$ of the city which are lacking inmanagement experience and social infrastructure systems, such as the projects Gamuda, Yen So park; South An Khanh. The Ministryalso stated that other compounds are also unmarketable and left vacant.

Most of these articles on the causes of the housing crisis in Vietnam described how financial debt and the lack of a proper regulatory structure allowed the housing bubble to grow and burst. Most of those articles suggest the solution to inhibit the crisis in Vietnam is measures controlling the financing system similar to the U.S., which may freeze capital for real estate, putting it into stagnation. However, not many articles noted thatthe cause of the housing crisis was that many financially incapable enterprises lacking experience entered the real estate market leaving the housing projects unfinished in Vietnam.

\subsection{Review of research that incorporates classical studies and contemporary portfolio theories regarding the rules of urban economics- sociology and contribute insights to the sustainability of housing development}

Christaller and Lösch Kathrin Fischer [13] represented the theories of Johann Heinrich vonThünen in thebook Der isolietre Staat in Beziehung auf Landwirtschaft und Nationalökonomie, in which VonThünen developed the first general equilibrium concept regarding the system of locations of economic activities. The theory explained why economic activities are concentrated in certain places (known as "central places") where an agglomeration of people and trade takes place, a problem relates with spatial economics [13].

Karin Wahl-Jorgensen [14] presented a broad but contemporary view about the Chicago School which has had a significant impact in the field of Sociology. In particular, the Chicago School gave voice to the idea that media and communications have a central role to play in shaping individual and collective lives today and described that how we communicate with each other and how the media shape our social bonds and social worlds [14].

Hoang Huu Phe, Tran Thanh Hung and Nguyen Thi My Linh [15] in their research Status - Quality Trade off Theory (SQTO) and its applications in public policies argued that cities have multi-polar structures, the poles of development as defined are the locations with highest social statuses. Thus, urban residential areas may form concentric belts (rings) around social status poles. Housing value is regarded as being composed from two elements: Housing Status (HS) of the location and Dwelling Quality (DQ) [15].

Large-Scale Urban Planning, Culture \& Environment: A Case Study in Saigon South Urban, a study prepared by John Kennedy [16] stated the habits and customs formed by the residents of Saigon South as well as the environmental has strong impact on the area. In this study, results from quantitative sample survey data and informal, formal and focus group interviews suggest that design choices that implement previous elements of culture and environment have had a positive impact on residents' perceptions of the environment which leads to the sustainability of the project as in Saigon South [16].

\section{Materials and Methods}

Following the previous research, this paper uses some suitable contemporary calculations from government institutions, commercial real estate services and investment firms in the world, and methodologies to assess the performance of real estate securities in the Vietnam 
Stock Exchange that represents for real estate investment and development in the country. The next part of the paper will discuss the data source and methodology used in this research. Following that is the discussion, implication and conclusion.

\subsection{Materials}

Materials are collected to show the causes of financial and housing crisis in the U.S. and Vietnam.

In the United States: In 2005, 1,283,000 new single-family houses were sold, compared with an average of 609,000 per year during 1990-1995. The housing bubble started when housing prices peaked in early 2006 then started to decline in 2007 and reached new lows in 2012.The following chart shows the rising quantity of houses built in the 2000-2007 period which is the consequence of loans with low mortgage interest rates provided by the banks.

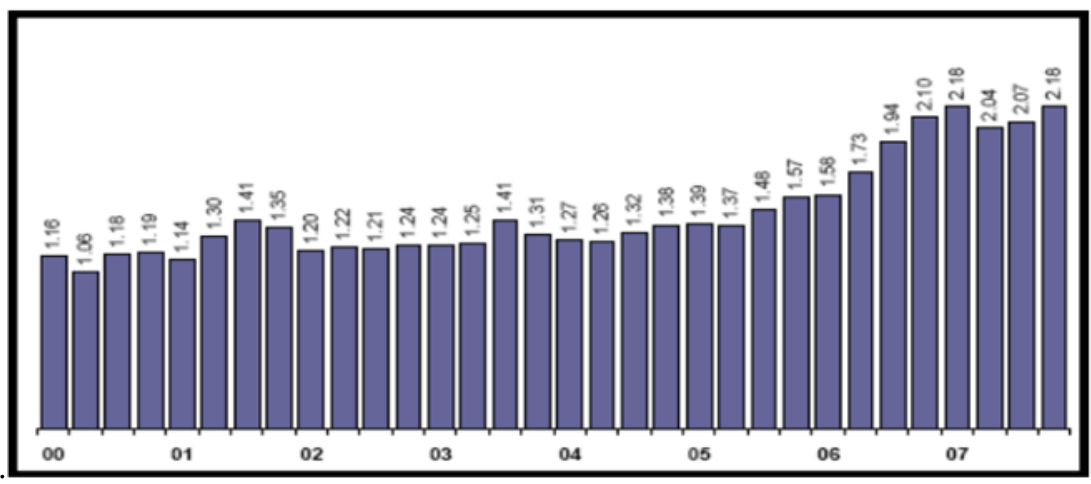

Fig. 1. Quantity of houses built in the 2000-2007 period in the US (Source: http://www.cuna.org).

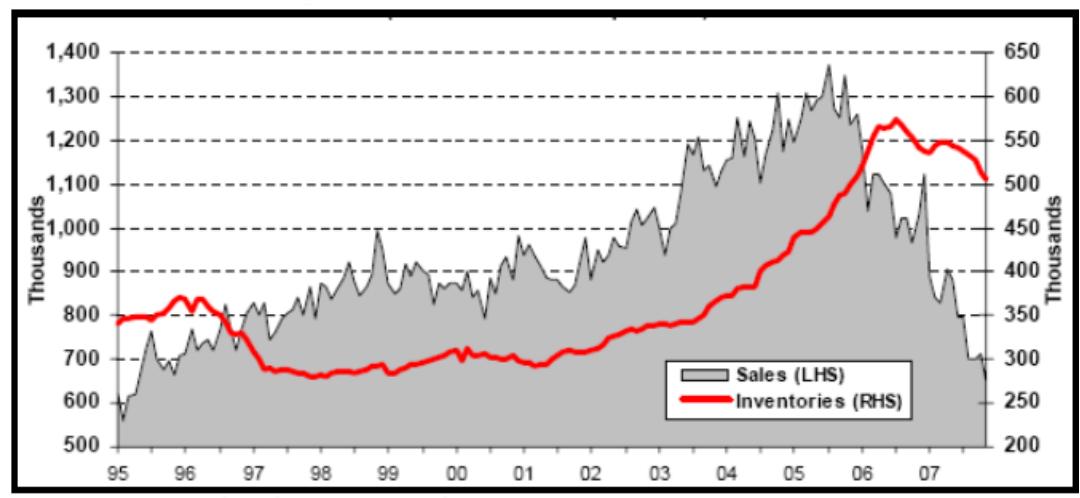

Fig. 2. Sales of Houses in the period 1995-2007 in the US (Source: http://www.cuna.org).

On December 30, 2008, the Case-Shiller home price index reported its largest price drop in its history. The bursting of the housing bubble led to increased mortgage foreclosures and caused the value of mortgage-backed securities to fall [5]. Many subprime loans were packaged into mortgage-backed securities (MBS) and ultimately defaulted, contributing to the financial crisis of 2007-2008. Mortgage-backed securities were often combined into collateralized debt obligations (CDOs), which may include other types of debt obligations.

The U.S government had to establish policies to protect the integrity of the financial system to solve the crisis: 
- Subsidies and bailout to stabilize the economy: The U.S. Secretary of the Treasury had to purchase distressed assets from financial institutions, especially mortgage-backed securities, and supply cash directly to bank. The Federal Reserve carries out a limited bailout for homeowners who were unable to pay their mortgage debts [17].

-Implement changes in policy to control the financial system:Policies of the U.S President such asa "Financial Regulatory Reform" were announced in June, 2009, preventing important financial institutions whose failure could threaten the entire system slip through the regulatory cracks. So in the U.S., unclogging the legal and financial system is regarded as the main key to the recovery and prevention of the crisis.

In Vietnam: When businesses made lower profits, this led a rush to invest in the real estate market of Vietnam, even from those primary investors who lack professionalism in housing development and knowledge of urban economics. The consequence is that many of the housing projects in Vietnam are set to fail from the start and their products cannot be sold or developed. Housing prices started to drop from 2008 (Fig. 3).

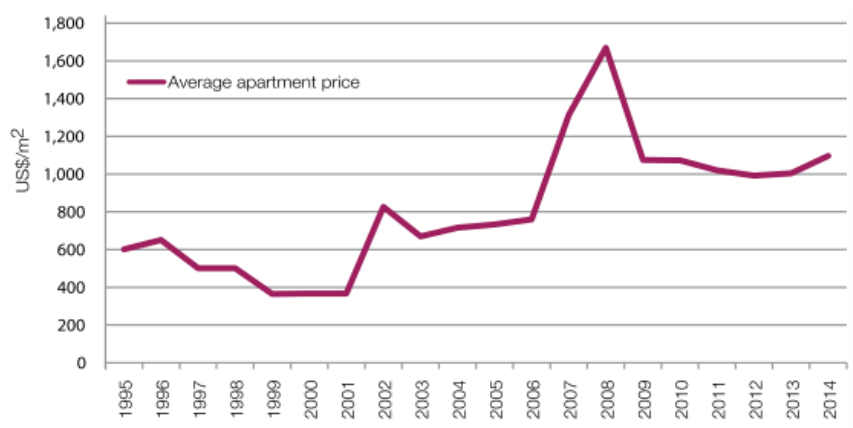

Fig. 3. Ho Chi Minh city Apartment Market Rate (\%) in Vietnam (Source Savills Research and Consultancy).

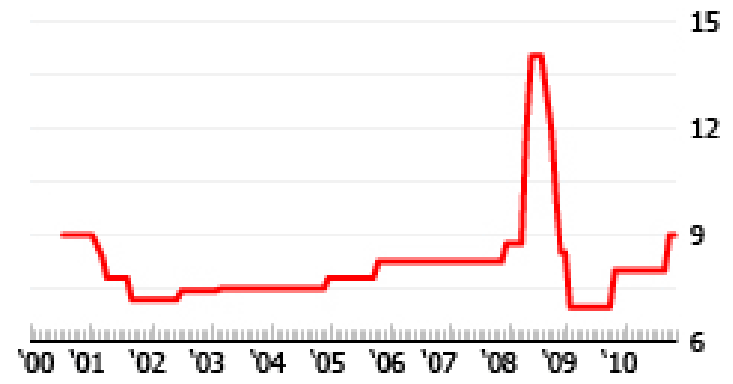

Fig. 4. Base Interest (Source: The State Bank of Vietnam).

As many financially incapable and inexperienced enterprisesentered the housing market with little professionalism.those primary investors were unable toachieve the feasibility of housing projects when provided inappropriate locations and infrastructure systems for theresidents of certain social groups. The bankruptcy rate of real estate companies increased by $24.1 \%$ in 2012 compared to 2011 , the loss companies accounted for $30 \%$, the bankruptcy companies in this year accounted for $4.7 \%$ of the total real estate and construction companies [12].

ACBRE report on quarter $1 / 2013$ stated that Hanoi has 21,600 unmarketable apartments, and that this rate has increased $21 \%$ incomparison with quarter $1 / 2012$. Further on, CBRE reported that within 9,000 apartments finished in the past 3 years, there are around $60 \%$ with 
no people living in them, and the reason is the lack of the infrastructure systems which are not finished yet.

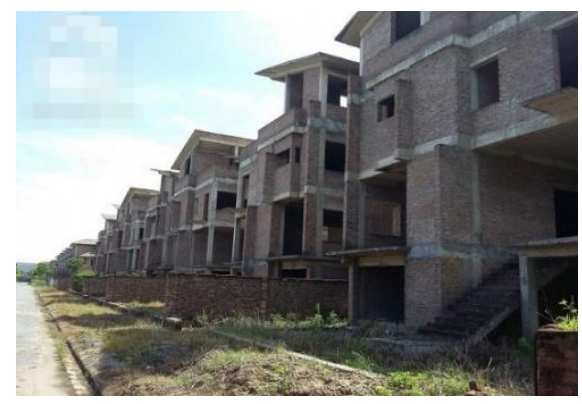

Fig. 5. Hanoi unfinished and unmarketable houses unfinished and unmarketable houses (Source: Tintuc.VN).

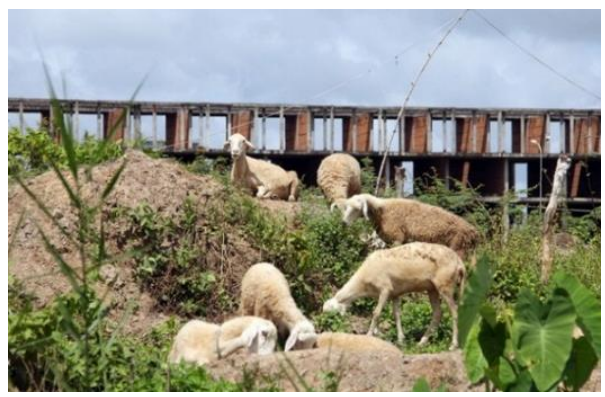

Fig. 6. Can Tho City (Source VT6 News).

Accordingly, the statistical data at the end of quarter 2/2014 provided by the Ministry of Construction showed that the instock rate of real estate products was equivalent to 92,690 billion VND, in which Hanoi contributed 3,096 low-rise apartments, mainly projects located far away from the CBD of the city which lack social infrastructure systems, such as the projects Gamuda, Yen So park; South An Khanh. The Ministry of Construction also stated that other compounds such as Lideco, Van Phú, Van Khe, An Hung... are also unmarketable, with thousands of bungalows left vacant.

\subsection{Methodology}

This part of the study aims to research a frameworkof theories identifying the features and nature of social segregation in the field of housing locationfor the formation of solutions for the housing sustainabilityand inhibition of the housing bubble in Vietnam by incorporate the rules of social segregation. The methodology here using both qualitative or quantitative methods, including a mixture of both, as the topics discussed here comes from an object that is both Sociology and Economics.

The quantitative methods of the article was based on the analysis of reports of the housing construction situation from Real estate agencies, news services and the Ministry of Construction The qualitative methods of the article was based on the analysis of the social nature of Urban housing development derived from researches of urban economics anh sociology.

\subsubsection{Urban Sociology theories related to the physical and social factors in recent urban residential zones}


- The Von Thunen Model.

The Von Thunen model (1783 - 1850) of agricultural land use hypothesized that there are four rings of agricultural activitiessurrounding the city which location depending on the transportation cost of certain types of products and thephysical distances to the center of the city. The price of land increases the closer it is to the city. The Von Thunenmodel is a fine illustration of the relation between land use separation and transportation cost [18].

-The models of the Chicago School.

In the twentieth century, one of the most enduring models of urban development has been the iconic "concentric zones" model by Chicago School sociologist Ernest Burgess and his University of Chicago colleague Robert Park. This concentric zones model suggests that cities grow steadily outward from the central business district (CBD).

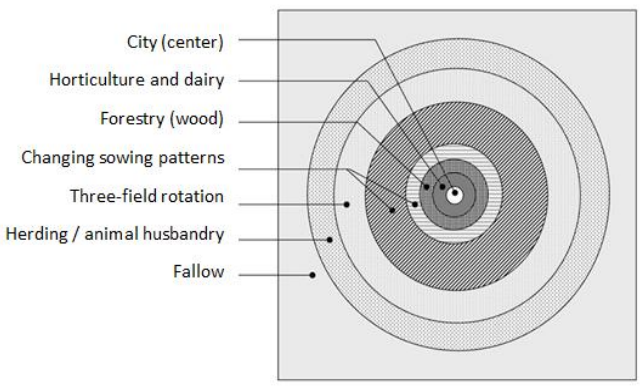

Fig. 7. The Von Thunen Model (Source: Ježek, 2002)

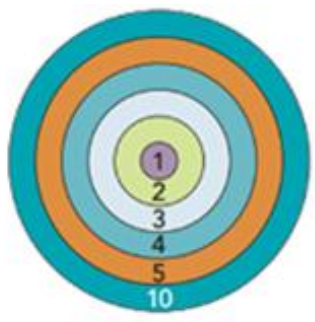

Concentric zones

$$
\text { Legend: }
$$

1.Central business district 2.Wholesale and light manufacturing 3.Low-class residential

4.Medium-class residential 5 . High-class residential 6 . Heavy manufacturing

7.Outlying business district 8 . Residential suburb 9 .Industrial suburb 10 .Commuter zone

Fig. 8. Three models of urban growth by Chicago school (Source: J. M. Henslin).

Surrounding the CBD core is a "circular ring in transition," with factories. Beyond this ring is the zone of tenements and apartments of the working class, next, the middle-class neighborhoods homes, and ultimately the ring of affluent commuter zones. The second Chicago School Sector model, proposed in 1932 by Homer Hoyt, is a modification of the concentric zone model. This model includes the fact it allows for an outward progression of growth. The third Chicago School model is the multiple nuclei model created by Chauncy Harris and Edward Ullman. It says that besides the first central business district, or CBD, other smaller CBDs develop on the outskirts of the city near the more valuable housing areas to allow shorter commutes from the outskirts of the city and creates nuclies in other parts of the city besides the CBD.

Andrew A. Beveridge, after the Chicago School models, considered the Los Angeles model, which argues that growth does not follow an orderly concentric pattern but, occurs in a sprawling fashion, as a multiplicity of commercial, industrial and residential areas spread 
outward without noticeable pattern. In addition, Beveridge associates with Jane Jacobs and William Whyte in the New York School, suggesting that the most economically productive districts and the most desirable residential areas and are concentrated in and around the city's dense center; growth in the periphery is less patterned [19].

Although recently, the contemporary post-industrial city urban development process and pattern has diverged in many ways that confound the Chicago classic model. The basic idea of the Chicago classic model still could be confirmed as there are rules between social segregation and the dwelling location and between social distances and communication distances. Theses rules work as long as market rules exists.

- Status, Quality and the Other Trade-Off (2000): Towards a New Theory of Urban Residential Location [15].

The study was carried out by Hoang huu Phe and Patrick Wakeley with the following main arguments:

Cities have multi-polar structures, the pole(s) of development are defined as the locations with highest social status. Social status may represent wealth, political or trading power, culture, race, education, etc. depending on the social forms; Urban residential areas form concentric belts (rings) around social status poles; Housing value is composed of 2 elements: Housing Status (HS) of the location and Dwelling Quality (DQ);Each value of HS has a corresponding DQ value. The locus of the locations creates a threshold surface in 3D space. This surface divides housing stock into two zones: The desirable zone and the undesirable zone; At lower value levels, housing price is determined mainly by use value. At higher value levels, the price is determined by exchange value

The differences between classic model and SQTO model are: Physical Centre (fixed) Status Centre (moving); Physical Distance - Calibrated Distance. The core results of the SQTO theory, which have allowed it to move a step further in the understanding of the city structure and its relation to the price of housing and real estate, can be divided into main groups, with important applications for the housing and real estate development policies [15].
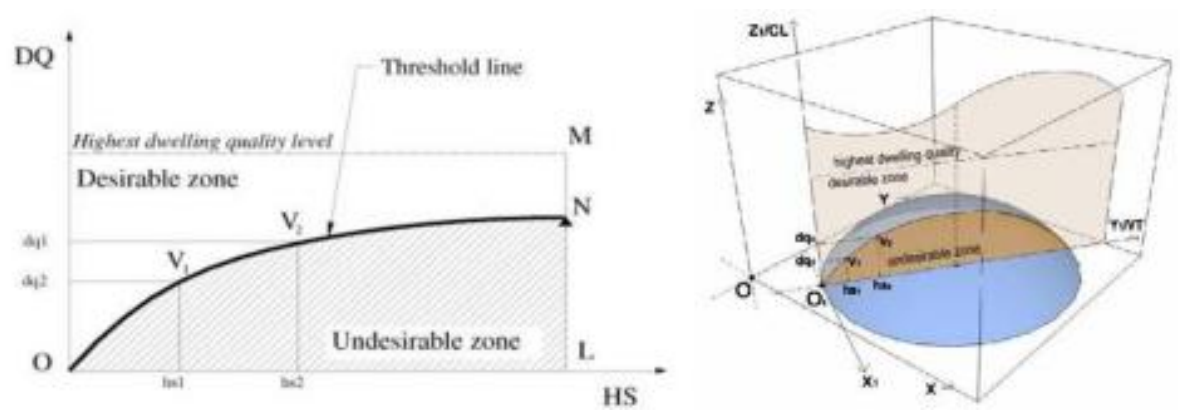

Fig. 9. Housing status (HS), Dwelling Quality (DQ) 2D and 3D Threshold Surface (Source: Hoang Huu Phe).

From an overall view: the theories mentioned above from Von Thunen to the Chicago School and other economists and sociologists proved that in the urban structure there exist relations between social order and physical space; between the physical distance of urban transportation and the social distance represented by the social segregation, following the natural selection rules of "survival of the fittest" of Darwinism, driven by the invisible hand.

\subsubsection{Role of social factors in the formation of the urban structure models}

Walter Firey in his famous published work "Man, Mind and Land. A theory of resource use" identified that market competition is not the only force that drives the formation of the urban 
structure; non-market power is also important. Some sociologists even claimed: "Social power could bend or blunt the market rules". That is why no cities are formed exactly as the models of Chicago school described. Social power can even change the social segregation situation by specific efforts. The worldwide financial crisis had also made clear that social powers such as psychological forces can even imperil the economic systems today.

The famous economist John Maynard Keynes used the term "animal spirits" to refer to emotional mindsets. George Akerlof and Robert Shiller acclaimed that "animal spirits", herd behavior and other social interactions are driving financial events worldwide. Both experts detail the most pervasive effects of the narrative stories telling each other about making economic fortunes [7].

\section{Results}

\subsection{The finding is the clarification of mistakes in the development of many housing projects in Vietnam}

Although not many of the Vietnamese financial institutions have suffered heavy losses due to the effects of this crisis, many economists in Vietnam still claimed that a country that is deeply integrating into the world economy cannot avoid the consequences of the crisis by specific solutions. [11], Although the crisis started right from the non-feasible projects of the primary investors, many economists and government institutes still focused on the financial sector, and proposed the two solutions similar to that of the U.S. in the lending of real estate investment which are:

-Financial Subsidiaries: Many banks have stepped up lending to the housing sector.

-The government executes strict monetary policies and restructures the banking system and has placed stronger financial requirements on property developers, strengthening control over debts.

In Vietnam, unclogging the legal and financial system cannot be regarded as the only main key to the recovery. Physical and social factors must be incorporated in the solutions as the housing bubble crashed also because most of the primary real estate developers are paying less attention to the rules of urban economics and sociology.

The wrong selection of location for the housing projects of which urban transportation capacity represented by the physical distance to the city center are not appropriate for inhabitants of certain social statuses is a fatal mistake of the housing projects. Low-income people cannot live in zones with long physical distance to the center of the city (CBD) as they find it difficult to approach their jobs or income sources. The primary investors who incorrectly believed that zones located far away from the center of the city with low land prices should be developed to house low-income people must be criticized. Low-income people have to accept residence in zones of low natural quality of living and low-cost facilities, but near to the core of the city, grouped in rings or sectors close to the CBD. Lowincome people demand open markets, not fine department stores. They demand public primary schools, not international schools, they are not be able to pay for gardeners or security guards.

High class people prefer fine environment quality and high-class housing zones, actually mostly in housing zones far away from the center of the city (CBD) where they can get a better environment and quality of life because the problem of travelling long distances could be easily overcome (commute) by their fine private vehicles. The success of the "University Village" and "Phú Mỹ Hưng" (fig. 10) housing project are strong evidences of this. A mistake is that many realty companies try to locate most of the high-class housing zones close to the 
center of the city where the natural air is heavily polluted and the populated density is high, where only a small number of rich people prefer to live.

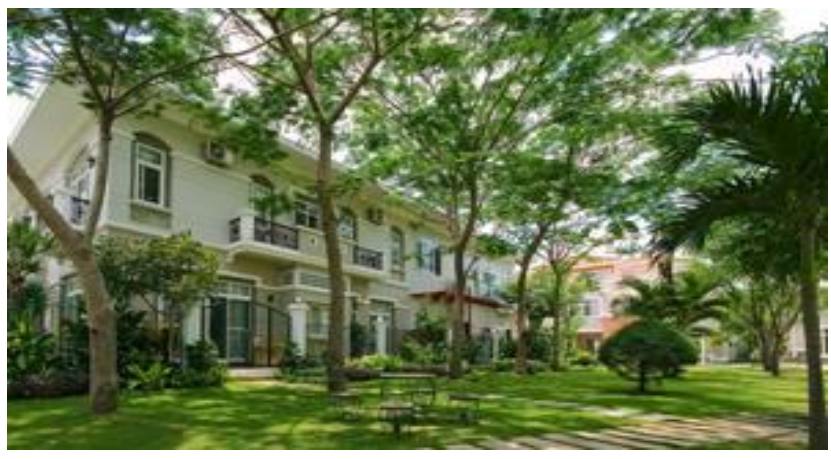

Fig. 10. The fine environment in Phu My Hung high provided with class housing area (Source: Phu My Hung company).

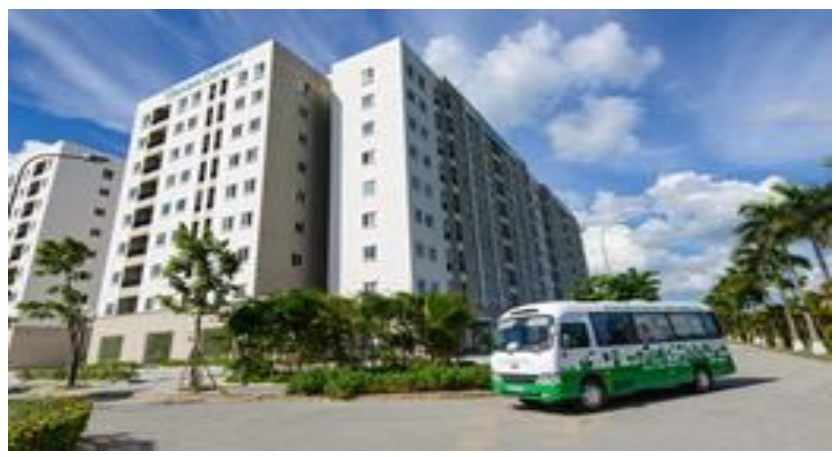

Fig. 11. A social housing area in Hanoi public transport facilities (Source: CEO group).

Some unfeasible projects even locate high class housing and low income houses together in the same compound without providing them the different appropriate social and technological infrastructure facilities. The consequence is that many of the housing projects cannot meet the functional demands and the market capacity of the end user from certain social statuses, high or low-income, leaving the market frozen with a huge number of unsold plots, houses, and apartments.

The analysis and evaluation of the feasibility of housing projects should be mostly carried on, such as: legal/statutory approvals, site environmental impact, the budget relative to stakeholders, housing prices affordable for client requirements, the potential to build [20], accommodation that might be included or excluded with possible juxtaposition of inhabitants from a diversity of social groups.

\subsection{Solutions for the formation of feasible housing projects, incorporating the physical and social factors}

-Encourage the primary investors to include urban economics and sociological factors to ensure the feasibility of their projects, especially the presence of sufficient urban transportation facilities in at the right selected locationfor the housing projects represented by the physical distance to the citycenter which are suitable for inhabitants ofcertain social statuses.

-Provide appropriate technical and social infrastructure facilities in the housing zones, adjustment and renovation of the existing infrastructure system planning in certain existing 
housing projects in order to be suitable with the demands of inhabitants of certain social status, particularly take full advantage of the possibilities of adjustment of the urban transportation.

-Implement improvement in financial policy, regulations, oversight, and enforcement in the housing financial system as strengthening monitoring and risk management tools by the state, concurrently with the above-mentioned measures in the field of urban economics and sociology as efforts of the state are necessary to manage animal spirits (as Keynes claimed) [21].

-Continue tight monetary policies from the state to check inflation from the central bank and to strengthen control over debts in housing finance, ensure the safety and soundness of the mortgage sector by enhancing prudent lending standards. Support development of specialized savings and subsidy-linked housing finance products, facilitate access to longterm funding in order to deepen the lending capacity of the financial sector.

\section{Conclusion}

The swift urbanization process in Vietnam has led to an outbreak of demands on the real estate business, which plays an important role. But will the application of the same main solution to solve the crisis - to "Ensure Stronger Regulation over Lending" as in the U.S solve the housing crisis in Vietnam? Will it be enough when not incorporating the rules of urban economics and urban sociology to provide sufficient and urban social facilities to housing zones?

The finding is that as long as market rules exist, social segregation in housing will happen. To create the most favorable conditions to promote investment in the real estate industry, to match up with the demand of the market driven by social forces, the solution for the formation of the feasibility of housing projects in Vietnam is to incorporate the physical and social factors in order to achieve the appropriate project location and dwelling quality.

\section{References}

1. R. Bookstaber, A Demon of Our Own Design: Markets, Hedge Funds, and the Perils of Financial Innovation, ISBN: 978-0-471-22727-4 (2007)

2. M.N. Baily, R.E. Litan, M.S. Johnson, The Origins of the Financial Crisis. The Initiative on Business and Public Policy at Brooklin, Fixing finance (2008)

3. D. Baker, Real-World Economics Review, 46 (2008)

4. J. Gwartney, D. Macpherson, R. Sobel, R. Stroup, The Crash of 2008: Cause and aftermath Teaching Resources on the Global Economic Crisis (Economics Private and Public Choice, 2009)

5. J. Holt, The Journal of Business Inquiry 8-1, 120-129 (2009)

6. R.J. Shiller, The Subprime Solution, How Today's Global Financial Crisis Happened, and What to Do About (Princeton University Press, Princeton, 2008)

7. G.A. Akerlof, R.J. Shiller, Animal spirits: how human psychology drives the economy, and why it matters for global capitalism, ISBN 9780691142333 (2009)

8. A. Mottaeva MATEC Web of Conferences 106, 08071 https://doi.org/10.1051/matecconf/201710608071

9. S.N. Jehan, Thanh Nga Luong, Vietnam's Real Estate Market: Can it Sail through the Capital Puzzle? (Ritsumeikan Asia Pacific University, 2008)

10. Lê Hồng Nhật, Scientific Journal of Economics and business 25, 207-216 (2009) 
11. Dang Huu Man, Scientific \& Technology magazine, 4(27) (2008)

12. N. Hong Quan, Minister of Construction, Report to the Vietnam National Assembly (2008)

13. Ch. Fischer, L.K. Fischer, ISOR 155, 471-505 (2011)

14. K. Wahl-Jorgensen, The Chicago School of Sociology and Mass Communication Research. The International Encyclopedia of Media Studies (2012)

15. H. Huu Phe, Tran Thanh Hung, N. Thi My Linh, Status - Quality Trade off Theory (SQTO) and its applications In Public Policies related To Urban Development and Real Estate Market (Vinaconex R\&D, 2013)

16. J. Kennedy, Large-Scale Urban Planning, Culture \& Environment: A Case Study in Saigon South Urban Independent Study Project (ISP) (2013)

17. M.A. Bahauovna, M.A. Bahauovna, International Journal of Applied Engineering Research 10(23), 43446-434499 (2015)

18. Do Cao, The vicious cycle of financial turmoil. China Liberation (2012)

19. P. Rene, Lectures on Urban economics at the University of Architecture HCMC (UAH, 2008)

20. R. Florida, The Most Famous Models for How Cities Grow Are Wrong (University of Rotman School of Management, 2013)

21. C.L. Flier, A. Thomsen, Research framework: Project feasibility assessment in Sustainable Urban Renewal (Real Estate \& Housing, 2005) 